\title{
Kolaylaştırıcı Okul Yapısı ve Örgütsel Vatandaşlık Davranışları Arasındaki İlişkinin İncelenmesi
}

\author{
DOI: 10.26466/opus.518009 \\ *
}

$\underline{\text { Sedat Alev }}{ }^{*}$

*Dr., MEB, Şahinbey Belediyesi Bilim ve Sanat Merkezi, Şahinbey/ Gaziantep / Türkiye

E-Posta: sedat alv@hotmail.com

ORCID: $\underline{0000-0003-4506-4756}$

Öz

Bu çalışmada, kolaylaştırıcı okul yapısı ile öğretmenlerin sergiledikleri örgütsel vatandaşlık davranışları arasındaki ilişkinin incelenmesi amaçlanmıştır. Araştırmada ilişkisel tarama modeli kullanılmıştır. Araştırmanın örneklemini, Gaziantep'te görev yapan 344 öğretmen oluşturmaktadır. Veri toplama aracı olarak, "Kolaylaştırıcı Okul Yapısı Ölçeği" ve "Örgütsel Vatandaşlık Davranışları Ölçeğì" kullanılmıştır. Araştırma verilerinin analizinde betimsel istatistikler, korelasyon ve regresyon analizi kullanılmıştır. Araştırma sonucunda, öğretmenlerin kolaylaştırıcı okul yapısı ve örgütsel vatandaşlık davranışı algılarının kısmen yüksek düzeyde olduğu belirlenmiştir. Korelasyon analizi sonucuna göre, kolaylaştırıcı okul yapısı ile örgütsel vatandaşlık davranışları arasında pozitif yönde bir ilişki bulunmaktadır. Regresyon analizi sonucunda, kolaylaştırıcı okul yapısının örgütsel vatandaşlık davranışını yordadığı belirlenmiştir. Ayrıca, kolaylaştırıcı okul yapısının öğretmenlerin örgütsel vatandaşlık davranışlarının yaklaşık \%39'unu açıkladı̆̆ı belirlenmiştir. Araştırma sonuçlarına dayalı olarak hem uygulayıcılar hem de araştırmacılar için çeşitli önerilerde bulunmak mümkündür.Okullarda çalışanların işlerini kolaylaştıran ve destek veren bir yapının oluşturulması gerekmektedir. Çünkü bu tür yapıya sahip olan okullarda güven odaklı bir kültürün oluşması ve çalışanların iş birlĭgi içerisinde okulun misyon ve vizyonunu yerine getirmeye istekli olmaları muhtemeldir. Okul yöneticilerinin öğretmenlerin yaptıkları işleri destekleyen bir tutum sergileyerek, olumlu bir iletişim ortamı oluşturmak için çaba göstermeleri, güven vermeleri ve bu sayede öğretmenlerin okulun yarar için ekstra işlerde gönüllü olarak görev almaları sağlanabilir.

Anahtar Kelimeler: Kolaylaştırıcı okul yapısı, örgütsel vatandaşlık davranışı, öğretmen. 


\title{
Examination of Relationship Between Enabling School Structure and Organizational Citizenship Behaviors
}

\begin{abstract}
In this study, it is aimed to reveal the relationship between enabling school structure and teachers' perceptions of organizational citizenship behaviors. The research designed in survey-based correlational model. The sample of the research consists of 344 teachers working in secondary schools in Gaziantep province. Enabling School Structure Scale and Organizational Citizenship Behaviors Scale are used as data collection tools. In the analysis of the data, descriptive statistics, correlation and regression are used. At the end of the research; perceptions of teachers' enabling school structure and organizational citizenship behaviors levels partly high. According to correlational analysis, there is a positive relationship between enabling school structure and organizational citizenship behaviors. As a result of regression analysis, it was determined that the enabling school structure predicted organizational citizenship behaviors. Besides, it is comfirmed that the research explains nearly the \%39 of the variance of teachers' perception of enabling school structure on organizational citizenship behaviours. Based on the results of the research, it is possible to make various suggestions for both practitioners and researchers. A structure that enabling and supports the work of the employees in schools should be created. Because in schools with such a structure, it is likely that a culture of trust to be formed and employees are willing to fulfill the mission and vision of the school in cooperation. School administrators can make an effort to create a positive communication environment by supporting the work of the teachers, providing reassurance, so that it can be ensured that the teachers can take part as a volunteer in extra work for the benefit of the school.
\end{abstract}

Keywords: Enabling school structure, organizational citizenship behaviors, teacher. 


\section{Giriş}

Örgütler, belirli bir görevi sürekli, ahenkli ve uyumlu olarak yapmak amacıyla bir kişinin yönetiminde teşkilatlanmış insan topluluğu olarak tanımlanmaktadır (Güney, 2011). Bir örgütün yapısı, iş gücünün özgün görevlere ayrıldığı ve sonra bunlar arasında koordinasyonun sağlandığ 1 yolların toplamı (Mintzberg, 2014) ve örgütteki bireylerin davranış-larının temel belirleyicisidir (Owens, 2004). Griffin ve Moorhead'a göre (2014) örgüt yapısı yapılan faaliyetlerin biçimini ve işlevini belirlemektedir. Başka bir ifadeyle, örgüt yapısı, örgütün hedeflerini gerçekleştirme sürecinde çalışanlar arasında iş bölümü ve koordinasyonu sağlamak için faaliyetlerin düzenlenmesidir. Birçok paydaşın (öğretmen, öğrenci, veli, vb.) bir arada bulunduğu okul ortamında, kaosun önlenmesi ve verimliliğin arttırılması için uygun şekilde tasarlanmış resmi prosedürlere ve hiyerarşik yapılara ihtiyaç vardır (Hoy ve Sweetland, 2001; Sinden, Hoy ve Sweetland, 2004). Bu nedenle, öğretme ve öğrenme sürecini etkili bir şekilde gerçekleştirmeyi amaçlayan ve bu amaç doğrultusunda belirli rol ve görevlerin kişilerin konumlarına göre şekillendiği okullarda, bürokrasinin varlığından söz etmek mümkündür (Yllmaz ve Beycioğlu, 2017).

Okullarda, genellikle kolaylaştırıcı ve engelleyici olmak üzere iki tür yapı bulunmaktadır (Hoy ve Miskel, 2010). Kolaylaştırıcı yapıya sahip okullarda öğretmenlerin karşılaştıkları sorunların çözümüne, öğretmenlerle yöneticilerin iş birliğine, öğretmenlerin karar alma sürecine katılmalarına yardım eden esnek kurallar vardır. Engelleyici yapıya sahip okullarda ise, öğretmenlere katı kuralların dayatıldığı ve onların yakından denetlendiği bir düzen bulunmaktadır (Bozkuş, 2016). Dolayısıyla kolaylaştırıcı yapıya sahip olan okullarda, öğretmenlerin görev tanımları dışında da çeşitli işlerde gönüllü olarak görev alacakları, diğer bir deyişle örgütsel vatandaşlık davranışı sergileyecekleri ifade edilebilir. Aktay ve Ekşi (2009) örgütsel vatandaşlık davranışlarının, emir vermeye dayalı olmayan, örgüte faydalı ve biçimsel olmayan davranışların yanı sıra, şikâyet etme gibi istenmeyen davranışların sergilenmesini azaltan davranışları da içerdiğini vurgulamaktadır. Çünkü günümüzde örgütlerin amaçlarını etkin bir şekilde gerçekleştirmesinde, maddi kaynakların niceliğinden çok, nitelikli insan gücüne sahip olmaları anlayışı önem kazanmaya başlamıştır.Çalışanların, örgütsel amaçları gerçekleştirmek 
amacıyla resmi görev tanımlarında bulunmayan ancak, çevresindeki diğer bireylere yardım ederek ya da görevin gereğinden fazlasını yaparak ekstra çaba göstermeleri, örgütün hedeflerine ulaşmasında oldukça önemli görülmektedir (Sezgin, 2005). Bu bağlamda,okullardaki bürokratik yapının öğretmenlerin sergiledikleri örgütsel vatandaşlık davranışları ile ilişkili olduğu görülmektedir.

\section{Kolaylaştırıcı okul yapısı}

Örgüt yapısı, bir örgütte görevlerin biçimsel olarak nasıl bölüneceği, iş akışının düzenlenmesi, karar alma sürecinde yetkinin nasıl kullanılacağ1nın ve çalışanlar arası ilişkilerin nasıl gerçekleştirileceğinin belirlenmesi (Covin ve Slevin, 1991), iş görevlerinin biçimsel olarak nasıl bölüneceği, sinıflanacağ1 ve koordine edileceği (Robbins ve Judge, 2013), örgütsel amaçları gerçekleştirmek için yöneticiler tarafından kabul edilmiş, örgütsel düzenlemeler ve ilişkiler bütünüdür (İçerli, 2009). Örgütsel yapı, örgütün fiziksel ve örgüt kültürü gibi soyut değerlerinden oluşmaktadır. Bir örgütün yapısı, hem amaçlara ulaşmak için gerekli etkinliklerin çalışanlar arasında nasıl bir iş bölümü ile dağıtıldığını, hem de görev ve fonksiyonların birbiriyle nasıl ilişkilendirildiğini de göstermektedir (Genç, 2007). Başka bir ifadeyle, örgütün yapısı, örgüt içerisinde gerçekleştirilen faaliyetler üzerinde etkili olmakta, çalışanlar arasında iş birliği ve koordinasyon sağlanarak örgütün amaçlarının etkin bir şekilde gerçekleştirilmesinde etkili olmaktadır.

Bürokrasi kavramı çoğu insan için, katı kurallar, otokratik yönetim, çalıştığı işe yabancılaşmış çalışanlar ile eş anlamlıdır. Fakat okullar da dahil olmak üzere farklı büyüklükteki organizasyonlar bürokratik yapılara sahiptirler (Buluç, 2009; Messick, 2012). Okullarda yapılan işlerin belirli kurallar dahilinde, belirlenen süre içerisinde gerçekleşmesi için, çalışanların verilen görevleri zamanında yapması önemlidir (Erdoğan, 2012). Dolayısıyla, okulların bürokratik örgütlerin birtakım özelliklerini kendi yapısına göre şekillendirerek sergiledikleri (Yılmaz ve Beycioğlu, 2017) ifade edilebilir.

Adler ve Borys (1996), bürokrasiyi kolaylaştırıcı ve engelleyici olmak üzere iki boyutta ele almıştır. Engelleyici bürokraside, bir örgütte çalışanların davranışları kontrol edilerek, kural ve prosedürlere uymayanları 
cezalandıran bir anlayış bulunmaktadır. Kolaylaştırıcı bir yapı ise, çalışanların işlerini engellemekten ziyade, sorunları çözmesinde onlara yardımcı olmaktadır (Hirschhorn, 1997). Diğer bir ifadeyle, kolaylaştırıcı bürokraside, çalışanlara rehberlik edilmekte, görev ve sorumluluklar belirlenmektedir (Hoy ve Miskel, 2010).

Okullardaki mevcut bürokratik yapı günümüz eğitim sisteminin ihtiyaçlarını karşılamakta kısıtlı kalmaktadır (Murphy, 2013). Hoy ve Sweetland (2001) bürokratik okul yapılarının hem olumlu hem de olumsuz sonuçlarını incelemiş ve daha sonra kolaylaştırıcı okul bürokrasisini mümkün kılmak için zıt iki görüşü birleştirmiş ve okullarda engelleyici bir yapıdan ziyade, çalışanların işlerini kolaylaştırıcı bir yapının oluşturulması gerektiğini vurgulamıştır. Okullarda kolaylaştırıcı bir yapının bulunması, çalışanlar arasında etkin bir iletişim ve güven ortamının oluşturulmasında ve ortaya çıan problemlerin çözümünde etkili olmaktadır (Hoy ve Sweetland, 2001; Sinden, Hoy ve Sweetland, 2004). Kolaylaştırıcı yapıya sahip okullarda, engelleme yerine yardım eden bir hiyerarşi olup, problem yaratan ya da başarısızlıkları cezalandıran değil, problemlerin çözümüne yol gösteren kurallar ve prosedürler vardır. Müdürler ve öğretmenler, farklı rollerini koruyarak ve kendi otorite sınırlarına bağlı kalarak iş birliği içerisinde çalışmaktadırlar. Hiyerarşi ve kurallar, müdürün gücünü arttırmak için bir araç olmaktan ziyade öğretmenleri destekleyen mekanizmalardır (Hoy ve Miskel, 2010). Bu tür yapıya sahip okullarda, öğretmenler ve yöneticiler birlikte çalışmakta, sorunların çözümü sürecinde ortak kararlar almakta; dolayısıyla öğretmenlerin görevlerini daha etkin bir şekilde yapmalarına yardımcı olan yapı ve destek sağlanmaktadır (Wu ve diğerleri, 2013).

Bürokratik yapının kolaylaştırıcı olduğu okullarda; problemler öğrenme fırsatları olarak görülmekte, çalışanlar mesleki açıdan kendilerini güçlü ve yeterli hissetmekte, yönetici ve çalışanlar arasındaki çatışmalar azalmaktadır (Özer ve Dönmez, 2013; Hoy ve Miskel, 2010). Kolaylaştırıcıokul yapıları, öğretmenlerin meslektaşlarıyla iş birliği çabalarını olumlu yönde etkileyerek okulun başarısında önemli rol oynamaktadır (Weick ve Sutcliffe, 2001). Ayrıca, okullarda çalışanların işlerini kolaylaştıran bir yapının ve yöneticinin bulunması öğretmenlerin sergiledikleri örgütsel vatandaşlık davranışlarının artmasını sağlamaktadır (Messick, 2012). Kisaca özetlemek gerekirse, okullarda öğretmenlerin 
işlerini kolaylaştıran, eğitim-öğretim faaliyetlerinde onları destekleyen bir yapının bulunması, sergileyecekleri örgütsel vatandaşlık davranışı üzerinde olumlu yönde bir etki oluşturacaktır.

\section{Örgütsel vatandaşlık davranışları}

İnsanın dikkate alınmaya başlandığı neoklasik dönemden itibaren insan örgütsel araştırmaların odak noktasında yer almaktadır. Bu noktada örgütsel vatandaşlık davranışı, bir insan olarak çalışanın kendisine biçilen rollerin dışında örgüt için fayda sağlayan faaliyetlere gönüllü katılımını ve sorumluluk almasını ön plana çıkaran bir yaklaşımdır (Tekin, 2018). Örgütsel vatandaşlık davranışı ilk olarak Organ (1988) tarafından sosyal değişim teorisinin bir parçası şeklinde ifade edilmiştir. Çalışanların performansı, görev tanımlarında yer alan ve gönüllü olarak sergilenen davranışlar olmak üzere iki şekilde olduğu belirtilmiş ve gönüllü olarak sergilenen davranışlar örgütsel vatandaşlık davranışı olarak ifade edilmiştir (Podsakoff, MacKenzie, Paine ve Bachrach, 2000). Diğer bir ifadeyle, örgütsel vatandaşlık davranışı, çalışanların resmi rol yükümlülüklerinde olmayan ekstra rol davranışlarıdır.

Literatürde yapılan araştırmalar incelendiğinde, örgütsel vatandaşlık davranışının, örgütsel destek (Somech ve Ron, 2007), lider-üye etkileşimi (Tekin, 2018), akademik iyimserlik (McGuigan ve Hoy, 2006), öğrenci başarısı (Wu, Hoy ve Tarter, 2013), psikolojik sermaye (Bozgeyikli, Avc1, Navruz, 2017; liderlik stilleri (Oğuz, 2011), örgütsel yapı (Messick, 2012) gibi çeşitli değişkenlerle ilişkisinin incelendiği görülmüştür. Bu araştırmaların sonucuna göre, örgütsel ortamda, çalışanların çevresindeki diğer bireylerle olan iletişimleri, yöneticilerin liderlik stilleri ve örgütün yapısı, örgütsel vatandaşlık davranışı ile yakın ilişki içerisinde bulunmaktadır.

Örgütsel vatandaşlık davranışı, yardımseverlik, vicdanlılık, sportmenlik, nezaket ve sivil erdem alt boyutlarından oluşmaktadır (DiPaola ve Tschannen-Moran, 2001). Yardımseverlik, bireyin, gönüllü olarak çalışma arkadaşlarına yardımcı olması (Avc1, 2015) vicdanlılık, olumsuz durumlarda dahi görevini aksatmama, işe vaktinde gelme, tamamlanması gereken bir iş için mesai saati dışında çalışmaktır (Çetin, Korkmaz ve Çakmakçı, 2012). Sportmenlik, olumsuzluklar karşısında şikâyet etmeden olumlu tutumu sürdürmeye çalışma (Dağlı ve Çalık, 2016), nezaket, bir 
davranışı sergilemeden önce düşünerek kontrollü hareket etme (Sezgin, 2005), sivil erdem ise, örgütün çıkarlarını en üst seviyede tutarak, örgütsel çalışmalara aktif ve gönüllü olarak katılma (Avc1, 2015) olarak ifade edilmektedir. Genel bir ifadeyle, öğretmenlerin, mesai saatleri dışında, okulun fiziki şartlarını iyileştirmek, öğrenci başarısını arttırmak gibi amaçlarla okulda bulunmaları, meslektaşlarına yardımcı olmaları, eğitimöğretim faaliyetlerinin etkili ve verimli bir şekilde devam ettirilmesine yönelik çalışmaları örgütsel vatandaşlık davranışları ile ilişkilidir.

\section{Kolaylaştırıcı okul yapısı ve örgütsel vatandaşlık davranışları}

Bürokrasinin okullarda aşırı katı ve kuralcı şekilde işlemesi, yöneticilerin kaynak konusunu her sorunun üzerinde görmeleri, emir-komuta zinciri içinde hesap vermeleri, bireyler arası ilişkilerin hiyerarşi, statü ve yetki sınırları içinde gerçekleştirilmesi gibi sorunlara neden olmaktadır (Buluç, 2008). Başka bir ifadeyle, alınacak kararların temelinde çeşitli yönetmelik ve genelgelerin yer alması, kişilerarası ilişkilerin belirli prosedürlere göre yürütülmesi, katı bir hiyerarşik yapının bulunması okul yapısının etkililiğini olumsuz yönde etkilemekte, çalışanların görev tanımları dışında ekstra rol göstermelerini engellemektedir. Fakat Somech ve Ron'un (2007) ifade ettiği gibi, öğretmenlik mesleğinin sorumlulukları oldukça fazladır ve öğretmenler zaman zaman görev tanımları dışında olmasına rağmen hem okulun hem de öğrencilerin yararına ekstra işlerde görev almak durumundadırlar. Bu nedenle öğretmenlerin ekstra işlerde görev alarak sergiledikleri örgütsel vatandaşlık davranışı, eğitim öğretim faaliyetlerinin sorunsuz bir şekilde geçmesi için önemli bir etkendir (Lambert, 2000).

Kolaylaştırıcı bir yapıya sahip olan okullarda, örgütsel vatandaşlık davranışının daha fazla gösterileceği ifade edilebilir. Nitekim Messick (2012) tarafından yapılan bir araştırmada, kolaylaştırıcı okul yapısının örgütsel vatandaşlık davranışını pozitif yönde etkilediği sonucuna ulaşılmıştır. Benzer doğrultuda, Yılmaz ve Beycioğlu (2017), işini severek yapan ve değer gördüğünü düşünen öğretmenlerin, işlerini daha iyi yapmak için harcadığı zamanın faydalı olduğunu hissetmelerinde ve yaptıkları işten tatmin olmalarında, görev yaptıkları okulun yapısı ve işleyişinin önemli bir etkiye sahip olduğunu vurgulayarak örgütsel vatandaşlık davranışı ve okul yapısı arasındaki ilişkiye atıfta 
bulunmuşlardır. Bu bağlamda, okullarda kolaylaştırıcı bir yapının bulunmasının öğretmenlerin sergiledikleri örgütsel vatandaşlık davranışlarını da olumlu yönde etkileyeceği ifade edilebilir.

\section{Araştırmanın Amacı}

Araştırmada, kolaylaştırıcı okul yapısının, örgütsel vatandaşlık davranışları ile ilişkisinin incelenmesi amaçlanmıştır. Bu amaç doğrultusunda aşağıda yer alan sorulara yanıt aranmıştır:

1. Öğretmenlerin kolaylaştırıcı okul yapısı ve örgütsel vatandaşlık davranışları algılarının düzeyi nedir?

2. Kolaylaştırıcı okul yapısı ve örgütsel vatandaşlık davranışları arasında istatistiksel olarak anlamlı bir ilişki var mıdır?

3. Kolaylaştırıcı okul yapısı, öğretmenlerin sergiledikleri örgütsel vatandaşlık davranışlarını yordamakta mıdır?

\section{Yöntem}

\section{Araştırma Modeli}

Kolaylaştırıcı okul yapısı ve örgütsel vatandaşlık davranışı arasındaki ilişkinin incelendiği araştırmada, nicel araştırma yöntemlerinden ilişkisel tarama modeli kullanılmıştır. İlişkisel model, iki ve daha fazla değişken arasında bir ilişki olup olmadığını ve/veya ilişkinin derecesini belirlemeyi amaçlayan bir araştırma modelidir (Fraenkel ve Wallen, 2006; Karasar, 2015).

\section{Evren ve Örneklem}

Araştırmanın evreni, 2018-2019 eğitim öğretim yılında Gaziantep ili Şahinbey ilçesindeki ortaokullarda görev yapan öğretmenlerden; örneklem ise bu evrenden oransız küme örnekleme yoluyla 25 farklı okuldan seçilen, toplam 344 öğretmenden oluşmaktadır. Veri toplama araçlarının geri dönüş oranı dikkate alınarak yaklaşık 600 öğretmene dağıtılan ölçek formundan geri dönen 365 ölçekten hatalı ve eksik kodlanan ölçekler çıkarıldıktan sonra kalan 344 ölçek üzerinde analizler 
yapılmıştır. \%95 güven düzeyi dikkate alındığında ölçek sayısının analiz için yeterli olduğu görülmektedir (Field, 2009). Örneklemde yer alan öğretmenlerin, 146's1 (\%42,4) erkek, 198'si $(\% 57,6)$ kadın öğretmenden oluşmaktadır. Bu öğretmenlerin 219'u (\%63,7) evli, 125'i $(\% 36,3)$ ise bekârdır. Öğretmenlerin yaş aralığı sırasıyla, 193 (\%56,1) 21-30 yaş, 126 $(\% 36,6)$ 31-40 yaş, $25(\% 7,3) 41$ ve üzeri yaştır. Kıdem bakımından ise öğretmenlerin 229'unun (\%66,6) 1-9 yıl, 95'inin (\%27,6) 10-19 yıl, 20'sinin $(\% 5,8) 20$ ve üzeri mesleki kıdeme sahip oldukları görülmektedir. Son olarak öğretmenlerin 322'sinin $(\% 93,6)$ lisans, 22'sinin $(\% 6,4)$ yüksek lisans derecesine sahip olduğu belirlenmiştir.

\section{Veri Toplama Araçları}

Araştırmada kullanılan ölçme araçları, katılımcıların kişisel bilgilerinin yer aldığı birinci bölüm; 12 maddeden oluşan kolaylaştırıcı okul yapısı ölçeğinin yer aldığı ikinci bölüm ve 12 maddeden oluşan örgütsel vatandaşlık davranışları ölçeğinin bulunduğu üçüncü bölüm olmak üzere toplam üç bölümden oluşmaktadır. Ölçekler 5'li Likert tipinde cevaplanmakta ve seçenekler, "Kesinlikle katılmıyorum (1)"; "Katılmıyorum (2)"; "Biraz katıliyorum (3)"; "Katıliyorum (4)"; ve “Tamamen katılıyorum (5)" şeklinde değerlendirilmektedir.

Kolaylaştırıcı Okul Yapısı Ölçeği: Hoy ve Sweetland (2001) tarafından geliştirilen, Buluç (2009) tarafından Türkçeye uyarlanan, Özer ve Dönmez (2013) tarafından psikometrik özellikleri yeniden incelenen ölçek, toplam 12 maddeden, engelleyici bürokrasi ve kolaylaştırıcı bürokrasi olmak üzere iki alt boyuttan oluşmaktadır. Ölçeğe ait Barlett Küresellik Testi sonucu anlamlı, Kaiser-Meyer-Olkin (KMO) katsayıs1,849 olarak bulunmuş ve veri setinin açımlayıcı faktör analizi (AFA) için uygun olduğu sonucuna varılmıştır. Engelleyici bürokrasi boyutunun açıkladığ 1 varyans \%37,601, kolaylaştırıcı bürokrasi boyutunun açikladığ1 varyans $\% 26,107$, iki boyut tarafından açıklanan toplam varyans ise \%63,738 olarak bulunmuştur. Cronbach's Alpha iç tutarlılık katsayısı, engelleyici bürokrasi boyutunda $(\mathrm{n}=4), 810$, kolaylaştırıc bürokrasi boyutunda $(\mathrm{n}=6)$ ,882, ölçeğin genelinde $(\mathrm{n}=10)$ ise ,830 olarak belirlenmiştir. Doğrulayıc1 faktör analizi (DFA) sonucunda, ölçeğe ait uyum değerlerinin $\left(X^{2}=47,233\right.$, 
sd=19， X2/sd=2,486， P=0,000， RMSEA=0,066， RMR=0,20， GFI=0,968， AGFI $=0,939$, NFI $=0.959, \mathrm{IFI}=0,975$, TLI $=0,963, \mathrm{CFI}=0,975)$ kabul edilebilir düzeyde olduğu görülmüştür (Sümer, 2000; Kline, 2011; Meydan ve Şeşen, 2015).

Örgütsel Vatandaşlık Davranışları Ölçeği: DiApola, Tarter ve Hoy (2005) tarafından geliştirilen, Taşdan ve Yılmaz (2008) tarafından geçerlik ve güvenirlik çalışmalarını yapılarak Türkçeye uyarlanan ölçek, toplam 12 madde ve tek boyuttan oluşmaktadır. Örgütsel Vatandaşlık Davranışları ölçeğinin faktör analizine uygun olup olmadığını belirlemek amaciyla yapılan analiz sonucunda Barlett Küresellik Testi sonucu anlamlı ve Kaiser-Meyer-Olkin (KMO) katsayısı ,908 olarak bulunmuştur. Bu sonuçlar veri setinin açımlayıcı faktör analizi (AFA) için uygun olduğunu göstermektedir. Tek boyuttan oluşan ölçeğe ait açıklanan varyans \%55,855 olarak belirlenmiştir. Ölçeğe ait Cronbach's Alpha iç tutarlılık katsayısı $(n=12), 908$ 'dir. Doğrulayıcı faktör analizi (DFA) sonucunda, ölçeğin tek boyutlu yapısı doğrulanmıştır. Elde edilen değerlerin $\left(X^{2}=38,294, \mathrm{sd}=18\right.$, $\mathrm{X}^{2} / \mathrm{sd}=2,127, \mathrm{P}=0,004$, RMSEA=0,057, RMR=0,19, GFI=0,974, AGFI=0,949, $\mathrm{NFI}=0,973, \mathrm{IFI}=0,986, \mathrm{TLI}=0,977, \mathrm{CFI}=0,985)$ kabul edilebilir değerlerde olduğu görülmektedir (Sümer, 2000; Kline, 2011; Meydan ve Şeşen, 2015).

\section{Verilerin Analizi}

Verilerin analizi aşamasında, aykırı (uç) değerler temizlenmiş, çarpıklık (Skewness) ve basıklık (Kurtosis) değerlerinin $-1,5$ ile $+1,5$ arasında olduğu belirlenmiştir. Bu sonuç değişkenlere ait verilerin normal dağılımda olduğunu göstermektedir (Tabachnick ve Fidell, 2013). Geçerlik güvenirlik çalışmaları kapsamında, ölçeklerin her biri için açımlayıcı faktör analizi (AFA) ve doğrulayıc faktör analizi (DFA) yapılmıştır. Cronbach's Alpha iç tutarlılık katsayıları incelenmiştir. Değişkenler arasındaki ilişkinin yönünü ve düzeyini belirlemek amacıyla Pearson korelasyon analizi yapılmıştır. Kolaylaştırıcı okul yapısının (bağımsız değişken), örgütsel vatandaşlık davranışlarını (bağımlı değişken) ne düzeyde yordadığını belirlemek için adımsal çoklu doğrusal regresyon analizi yapılmıştır. 


\section{Bulgular}

\section{Değişkenlere ait betimsel istatistikler ve korelasyon katsayıları}

Değişkenlere ait betimsel istatistikler (aritmetik ortalama, standart sapma ve standart hata değerleri) ile değişkenler arası ilişkilerin yönünü ve düzeyini gösteren korelasyon değerleri aşağıdaki Tablo 1'de yer almaktadir.

Tablo 1.Değişkenlere Ait Betimsel İstatistikler ve Korelasyon Katsayıları

\begin{tabular}{lccccc}
\hline Değişkenler & $\mathbf{N}$ & $\overline{\mathbf{X}}$ & ss. & $\mathbf{1}$ & $\mathbf{2}$ \\
\hline 1. Kolaylaştırıcı Okul Yapısı & 344 & 3,68 &, 82 & 1 & \\
2. Örgütsel Vatandaşlık Davranışları & 344 & 3,81 &, 72 &, $619^{* * *}$ & 1 \\
\hline
\end{tabular}

${ }^{*} \mathrm{p}<.05{ }^{* *} \mathrm{p}<.01$

Tablo 1'de yer alan değerler incelendiğinde, kolaylaştırıcı okul yapısı ve örgütsel vatandaşlık davranışlarına yönelik öğretmen algılarının kısmen yüksek düzeyde olduğu görülmektedir. Başka bir ifadeyle, öğretmeler okullarının kolaylaştırıcı bir yapıya sahip olduğunu ve örgütsel vatandaşlık davranışları sergilediklerini ifade etmektedirler. Korelasyon analizi sonucunda, kolaylaştırıcı okul yapısı ve örgütsel vatandaşlık davranışları arasında pozitif yönde, orta düzeyde bir ilişki olduğu belirlenmiştir.

\section{Kolaylaştırıcı okul yapısının örgütsel vatandaşlık davranışlarını yorda- masi}

Araştırmada kolaylaştırıcı okul yapısı yordayıcı (bağımsız) değişken, örgütsel vatandaşlık davranışları ise yordanan (bağımlı) değişken olarak ele alınmıştır. Yapılan çoklu regresyon analizinde, birinci adımda sonuçlar üzerinde etki edeceği düşünülen cinsiyet (dummy), yaş ve kıdem değişkenleri kontrol altına alındıktan sonra, ikinci adımda enter yöntemi ile kolaylaştırıcı okul yapısı modele eklenmiştir. Analiz sonucu ortaya çıkan değerler aşağıdaki Tablo 2' de sunulmuştur. 
Tablo 2. Kolaylaştırıcı Okul Yapısının Örgütsel Vatandaşlık Davranışlarını Yordamasına İlişkin Regresyon Analizi Sonucu

\begin{tabular}{|c|c|c|c|c|c|c|}
\hline Model & Yordayıcı değişkenler & $\mathrm{B}$ & Std. Hata & $\beta$ & $\mathrm{t}$ & $\mathrm{p}$ \\
\hline \multirow{4}{*}{$\begin{array}{l}\text { 1.adım } \\
\text { (enter) }\end{array}$} & (Sabit) & 3,76 & 33 & & 11,28 &, $00^{* * *}$ \\
\hline & Cinsiyet (dummy) &,- 07 & ,07 &,- 06 &,- 99 & ,32 \\
\hline & Yaş & ,00 & 01 & ,03 & 24 & 81 \\
\hline & Kıdem & 00 & 01 & 01 & ,04 & 97 \\
\hline \multirow{5}{*}{ 2. adim } & (Sabit) & 1,48 & ,30 & & 4,93 &, $00^{* * *}$ \\
\hline & Cinsiyet (dummy) &,- 01 & 07 &,- 08 & $-1,69$ & ,09 \\
\hline & Yaş &,- 01 & 01 &,- 07 &,- 66 &, 51 \\
\hline & Kidem & 01 & ,01 & 15 & 1,33 & ,18 \\
\hline & Kolaylaştırıcı okul yapısı & 68 & ,05 & 63 & 14,85 &, $00^{* * *}$ \\
\hline
\end{tabular}

Tablo 2'de görüldügüü üzere, yapılan çoklu regresyon analizde, kişisel değişkenler cinsiyet, yaş ve kıdem birinci adımda kontrol altına alınarak ikinci adımda kolaylaştırıcı okul yapısı modele eklenmiştir. Kolaylaştırıcı okul yapısının öğretmenlerin sergiledikleri örgütsel vatandaşlık davranışlarını pozitif yönde anlamlı bir şekilde yordadığı sonucuna varılmıştır $\left(\beta=0,63^{* * *}, \mathrm{p}<0,01\right)$. Kolaylaştırıcı okul yapısındaki 1 birimlik artış örgütsel vatandaşlık davranışlarında 0,63 birimlik bir artışa neden olmaktadır. Örgütsel vatandaşlık davranışlarının \%39,2'si kolaylaştırıcı okul yapısı tarafından açıklanmaktadır $\left(\Delta \mathrm{R}^{2}=, 392, \mathrm{p}<0,01\right)$. Başka bir deyişle, okullarda kolaylaştırıcı bir yapı olduğu zaman öğretmenler daha fazla örgütsel vatandaşlık davranışı sergilemektedirler.

\section{Tartışma, Sonuç ve Öneriler}

Kolaylaştırıcı okul yapısı ve örgütsel vatandaşlık davranışlarına dair ortaokul örnekleminde yapılan bu araştırmada, öğretmenlerin kolaylaştırıcı okul yapısı ve örgütsel vatandaşlık davranışları algılarının kısmen yüksek düzeyde olduğu sonucuna varılmıştır. Diğer bir ifadeyle, öğretmenler görev yaptıkları okulların kolaylaştırıcı bir yapıya sahip 
olduğunu ve görevlerini yaparken ekstra davranışlarda bulunarak, örgütsel vatandaşlık davranışları sergiledikleri yönünde görüş belirtmişlerdir. Araştırma bulgularına benzer şekilde yapılan araştırmalarda (Messick, 2012; Yılmaz ve Beycioğlu, 2017), öğretmenlerin görev yaptıkları okulların bürokratik yapısını destekleyici, demokratik, adil ve işlerini kolaylaştırıcı özelliklere sahip olarak nitelendirdikleri sonucuna ulaşılmıştır. Buna ek olarak örgütsel vatandaşlık davranışları ile ilgili olarak yapılan araştırmalarda da (Somech ve Drach-Zahavy, 2000; Bogler ve Somech, 2004; Yaylac1, 2004; Bragger vd., 2005; Polat ve Celep, 2008; Buluç, 2008; Yılmaz ve Taşdan, 2009; Titrek, Bayrakçı ve Zafer, 2009; Belogolovsky ve Somech, 2010) öğretmenlerin örgütsel vatandaşlık davranışlarını kısmen yüksek düzeyde olduğu sonucuna ulaşılmıştır. Görüldüğü üzere, araştırmadan elde edilen bulgular, öğretmenlerin kolaylaştırıcı okul yapısı ve örgütsel vatandaşlık davranışları ile ilgili yapılan çalışmaların sonucu ile benzerlik göstermektedir.

Okullarda engelleyici bir yapıdan ziyade, çalışanların işlerini kolaylaştıran bir yapının oluşturulması gerekmektedir (Hoy ve Sweetland, 2001). Çünkü bürokratik yapının kolaylaştırıcı olduğu okullarda öğretmenler, insan ilişkilerine önem veren ve çözüm odaklı olan yöneticilere karşı olumlu bir tutum sergilemektedirler (Can, 2010). Bunun sonucunda ise öğretmenlerde iş birliği içerisinde çalışma isteği oluşmaktadır (Matsuda ve Matsuda, 2001). Benzer şekilde, Özgür (2011) de görev yaptıkları okullarda karşılıklı iyi niyet ve güven ortamında çözümlerin üretildiği ve anlaşmazlıkların giderildiği bir yapı olduğunu düşünen öğretmenlerin motivasyonlarının arttığ1 ve iş birliği içerisinde çalıştıklarını; ancak otoriter bir yönetim anlayışının benimsendiği, baskıcı ve tehditkâr davranışların hâkim olduğu bir okul yapısında ise kendilerini rahatsız hissedeceklerini belirtmiştir.

Araştırmadan elde edilen bir diğer bulgu, kolaylaştırıcı okul yapısı ile örgütsel vatandaşlık davranışları arasında pozitif yönde bir ilişki olduğu sonucudur. Görüldüğü üzere, kolaylaştırıcı yapıya sahip okullarda, öğretmenlerin görev tanımları dışında da çeşitli görev ve sorumluluklar almaya istekli olacakları, dolayısıyla daha fazla örgütsel vatandaşlık davranışları sergileyecekleri ifade edilebilir. Bu konuda, Messick (2012) tarafından yapılan araştırmada, kolaylaştırıcı okul yapısının örgütsel vatandaşlık davranışlarını pozitif yönde etkilediği sonucuna ulaşılmıştır. 
Benzer şekilde, Yılmaz ve Beycioğlu (2017) da işini severek yapan ve değer gördüğünü düşünen öğretmenlerin, işlerini daha iyi yapmak için harcadığı zamanın faydalı olduğunu hissetmelerinde ve yaptıkları işten tatmin olmalarında, görev yaptıkları okulun yapısı ve işleyişinin önemli bir etkiye sahip olduğunu vurgulayarak örgütsel vatandaşlık davranışları ve okul yapısı arasındaki ilişkiye atıfta bulunmuşlardır.

Araştırmada, kolaylaştırıcı okul yapısının örgütsel vatandaşlık davranışlarını yordamasına yönelik olarak yapılan adımsal çoklu doğrusal regresyon analizinde, sonuçlar üzerinde etkisi olacağı düşünülen cinsiyet, yaş ve kıdem gibi kişisel değişkenler kontrol altına alındıktan sonra, kolaylaştırıcı okul yapısının öğretmenlerin sergiledikleri örgütsel vatandaşlık davranışlarını yordadığı bulgusu elde edilmiştir. Diğer bir ifadeyle, öğretmenlerin, okullarında yapılan iş ve işlemlerde çalışanları engelleyici bir yapıdan ziyade, destekleyici bir yapının olduğunu düşünmeleri, onların görev tanımları dışında da okulun yararına ekstra rol üstlenmelerini, okula karşı olumlu bir tutum oluşturmalarını sağlamaktadır. Nitekim, okulların başarısının temelde, okulun hedeflerine ve değerlerine bağlı olan (Oplatka, 2006), görev tanımından fazlasını yapmaya çalışarak okulun gelişimine katkıda bulunmaya istekli öğretmenlere bağlı (Bogler ve Somech, 2004; Belogolovsky ve Somech, 2010) olması, öğretmenlerin örgütsel vatandaşlık davranışları sergilemelerinin önemli ve gerekli olduğunu göstermektedir.

Okullarda kolaylaştırıcı bir yapının bulunması, öğretmenlerin kendi aralarında ve öğretmen-yönetici arasında etkin bir iletişim ve güven ortamının oluşturulmasında ve ortaya çıan problemlerin çözümünde etkili olmaktadır (Hoy ve Sweetland, 2001; Sinden, Hoy ve Sweetland, 2004). Örgütsel güvenin yüksek olması ise çalışanların yaptıkları işlere odaklanmalarına yardımcı olmakta ve dolayısıyla çalışanların görevlerini yerine getirmeleri ve örgütsel vatandaşlık davranışları göstermelerine katkı sağlamaktadır (Konoysky ve Pugh 1994; Brockner, vd., 1997; Tokgöz ve Seymen, 2013). Bu bağlamda, kolaylaştırıcı bir yapının bulunduğu okullarda öğretmenlerin güven düzeyinin yüksek olacağı ve bu durumun öğretmenlerin sergiledikleri örgütsel vatandaşlık davranışlarını olumlu yönde etkiyeceği ifade edilebilir. Bunun aksine bürokratik yapının engelleyici olduğu okullarda ise güven düzeyinin azalmakta ve çalışanlar daha az örgütsel vatandaşlık davranışı sergilemektedirler (Samancı, 2007; 
Yılmaz, 2009). Diğer bir ifadeyle, çalışanların görev tanımlarında olmayan işlerde gönüllü olarak yer alması, mesai saatleri dışında da örgütün ve diğer çalışanların yararına olacak işlerde görev alması için öncelikle güven duygusunun olması gerekmektedir. Güven duygusunun oluşması için de çalışanların işlerini kolaylaştıran, onlara destek olan bir yapının oluşturulması gerekmektedir. Bu konuda Yılmaz ve Beycioğlu (2017) tarafından yapılan bir araştırma sonucunda, kolaylaştırıcı bürokratik yapının özellikleri kapsamında öğretmenlerin; karar alma süreçlerinde katılımcı bir yaklaşım benimsendiğine, iş bölümüne önem verildiğine, herkesin görevinin gereklerini yerine getirdiğine, kural ve prosedürlerin zaman zaman esneklik gösterdiğine ve yöneticiler tarafından izlenen bir takım olumlu stratejilere değindik-leri görülmektedir. Dolayısıyla kolaylaştırıcı okul yapıları öğretmenlerin örgütsel vatandaşlık davranışları üzerinde olumlu bir etkiye sahiptir.

Araştırma sonuçlarına dayalı olarak hem uygulayıcılar hem de araştırmacılar için çeşitli önerilerde bulunmak mümkündür. Okullarda çalışanların işlerini kolaylaştıran ve destek veren bir yapının oluşturulması gerekmektedir. Çünkü bu tür yapıya sahip olan okullarda güven odaklı bir kültürün oluşması ve çalışanların iş birliği içerisinde okulun misyon ve vizyonunu yerine getirmeye istekli olmaları muhtemeldir. Dolayısıyla öğretmenlerin okuldaki faaliyetlerde etkin bir şekilde rol alarak daha fazla örgütsel vatandaşlık davranışları sergileyecekleri düşünülmektedir. Bunun yanı sıra, okul yöneticilerinin öğretmenlerin yaptıkları işleri destekleyen bir tutum sergileyerek, olumlu bir iletişim ortamı oluşturmak için çaba göstermeleri, güven vermeleri ve bu sayede öğretmenlerin okulun yararı için ekstra işlerde gönüllü olarak görev almaları sağlanabilir.

Bu çalışmada, kolaylaştırıcı okul yapısının örgütsel vatandaşlık davranışları ile ilişkisi incelenmiştir. Bundan sonra yapılacak çalışmalarda, kolaylaştırıcı okul yapısı ve örgütsel vatandaşlık davranışları ile ilişkili olduğu düşünülen değişkenlerle (okul kültürü, örgütsel bağl1lık, örgütsel sessizlik, örgütsel adalet, duygusal emek, liderlik vb.) araştırmalar yapılabilir. Ayrıca, farklı örneklemlerle araştırma yapılarak sonuçlar karşılaştırılabilir. Değişkenler arasındaki ilişkilerin nedenlerine yönelik olarak nitel veya karma yöntemde araştırmalar yapılabilir. 


\section{EXTENDED ABSTRACT}

\section{Examination of Relationship Between Enabling School Structure and Organizational Citizenship Behaviors \\ *}

\section{Sedat Alev}

Organizations are defined as compositions of people that are organized under the tutelage of a person to fulfil a duty perpetually, harmoniously and congruously (Güney, 2011). The structure of an organization is the sum total of the ways in which it divides its labour into distinct tasks and then achieves coordination among them (Mintzberg, 2014) and the key determinant of the behaviours of the persons in the organization (Owens, 2004). Structure defines the form and function of the organization's activities according to Griffin and Moorhrad (2014). In other words, the organizational structure is the regulation of activities to ensure the division of labor and coordination among the employees in the process of achieving the objectives of the organization. In the school setting where many sharers (teachers, students, parents, etc.) co-exist, there is a need for need appropriately designed formal procedures and hierarchicalstructures to prevent chaos and promote efficiency (Hoy and Sweetland, 2001; Sinden, Hoy and Sweetland, 2004). Therefore, it is possible to talk about the existence of bureaucracy in schools where specific roles and tasks are shaped according to the positions of the individuals, aiming to carry out the teaching and learning process efficaciously (Yılmaz and Beycioğlu, 2017). The fact that bureaucracy functions in schools in an excessively strict and prescriptive way causes the problems of executives to see the source subject above every other problem, account within the chain of command, and the relations between the individuals being realized within the hierarchy, status and authority limits (Buluç, 2008). In other words, the involvement of various regulations and circulars on the basis of the decisions to be taken, interpersonal relations being conducted in accordance with certain procedures, the existence of a strict hierarchical structure negatively affect 
the efficacy of the school structure and hinders employees to play an extra role aside from their job descriptions. It can be stated that organizational citizenship behavior shall be demonstrated more in schools with an enabling structure. As a matter of fact, in a research conducted by Messick (2012), it was concluded that the enabling school structure positively affected the organizational citizenship behavior. In a similar way, Yilmaz and Beycioğlu (2017) have referred to the relationship between organizational citizenship behaviour and school structure by emphasizing that structure and functioning of the schools they worked have important effects on teachers who do their job fondly and think they are valued feel that the time they spend to do their jobs better is beneficial and they are satisfied with their work. In this regard, a enabling structure being present in schools will positively affect the organizational behaviours of the teachers.

The aim of this research was to investigate the relationship between enabling school structure and organizational citizenship behaviors. In line with this objective, answers to the following questions were sought:

1. What is the level of teachers' perception of enabling school structure and organizational citizenship behaviors?

2. Is there a statistically significant relationship between the enabling school structure and organizational citizenship behaviors?

3. Does the enabling school structure predict the organizational citizenship behaviors of teachers?

\section{Method}

In this research that the relationship between enabling school structure and organizational citizenship behaviors was investigated relational screening model of quantitative research methods was used. A relational model is a research model that aims to determine the relationship between two and more variables and/or to determine the degree of the relationship (Fraenkel and Wallen, 2006; Karasar, 2015). The population of the research is from the teachers who work in secondary schools in Şahinbey district of Gaziantep in the 2018-2019 academic year; the sample consists of 344 teachers, selected from 25 different schools through the disproportionate cluster sampling from this population. 
The measurement tools used in the research consist of a total of three parts, first part includes the participants' personal information; the second part includes the facilitating school structure scale consisting of 12 items and the third part includes organizational citizenship behaviors scale consisting of 12 items

In the analysis of the data, the contrary values were cleared, skewness and kurtosis values were determined to be between -1.5 and +1.5 . This result shows that the data of the variables are in normal distribution (Tabachnick and Fidell, 2013). In the scope of validity researches, exploratory factor analysis (AFA) and confirmatory factor analysis (CFA) were performed for each scale. Cronbach's Alpha internal consistency coefficients were examined. Pearson correlation analysis was performed to determine the direction and level of relationship between variables. Stepwise multiple linear regression analysis was conducted to determine the level at which enabling school structure (independent variable) affects organizational citizenship behavior (dependent variable).

\section{Results}

In this research conducted in the middle school sample regarding enabling school structure and organizational citizenship behaviors, it was concluded that teachers' perception of school structure and organizational citizenship behaviors were partially high. In other words, teachers stated that the schools they work have a enabling structure and that they exhibit organizational citizenship behaviors by performing extra duties while performing their duties. In the researches that are similar to the findings of this research (Messick, 2012; Yılmaz and Beycioğlu, 2017), it was concluded that teachers described the bureaucratic structure of the schools they work as having democratic, fair and facilitating characterizations As a result of the research, it was found that there was a positive relationship between the enabling school structure and organizational citizenship behaviors and the enabling school structure predicted the organizational citizenship behaviors.

Based on the results of the research, it is possible to make various suggestions for both practitioners and researchers. A structure that enabling and supports the work of the employees in schools should be created. 
Because in schools with such a structure, it is likely that a culture of trust to be formed and employees are willing to fulfill the mission and vision of the school in cooperation. Therefore, it is thought that teachers will have more organizational citizenship behaviors by taking an active role in school activities. In addition to this, school administrators can make an effort to create a positive communication environment by supporting the work of the teachers, providing reassurance, so that it can be ensured that the teachers can take part as a volunteer in extra work for the benefit of the school. The results can be compared by researching with different samples. Qualitative or mixed methods can be researched intended for the reasons of the relationships between the variables.

\section{Kaynakça / References}

Adler, P. ve Borys, B. (1996). Two types of bureaucracy: Enabling and coercive. Administrative Science Quarterly, 41, 61-89.

Aktay, A. ve Ekşi, H. (2009). Yönetici ve öğretmenlerin değer tercihleri ile örgütsel vatandaşlık davranışları arasındaki ilişki. İşs Ahlakı Dergisi, 2(1), 19-65.

Avcı, A. (2015). Örgütsel vatandaşlık davranışları: kavramsal gelişimi ve eğitim örgütleri açısından etkileri. Hasan Ali Yücel Eğitim Fakültesi Dergisi, 12(2), 11-26.

Belogolovsky, E. ve Somech, A. (2010). Teachers' organizational citizenship behavior: Examining the boundary between in-role behavior and extra-role behavior from the perspective of teachers, principals and parents. Teaching and Teacher Education, 26(4), 914-923.

Bogler, R. ve Somech, A. (2004). Influence of teacher empowerment on teachers' organizational commitment, professional commitment and organizational citizenship behavior in schools. Teaching and Teacher Education, 20(3), 277-289.

Bozgeyikli, H., Avc1, A. ve Navruz, B. (2017). Öğretmenlerin psikolojik sermaye düzeyleri ile örgütsel vatandaşlık davranışları arasındaki ilişkinin yapısal eşitlik modeli ile incelenmesi. TURKISH STUDIES -International Periodical for the Languages, Literature and History of Turkish or Turkic-, 12(6) 103-122. 
Bozkuş, K. (2016). Örgüt yapısı ve okullar. Kesit Akademi Dergisi, 2(4), 236260.

Bragger, J. D., Rodriguez-Srednicki, O., Kutcher, E. J., Indovino, L. ve Rosner, E. (2005). Work-family conflict, work-family culture, and organizational citizenship behavior among teachers. Journal of Business and Psychology, 20(2), 303-324.

Brockner, J., Siegel, P. A., Daly, J. P., Tyler, T. ve Martin, C. (1997). When trust matters: The moderating effect of outcome favorability. Administrative Science Quarterly, 42(3), 558-583.

Buluç, B. (2008). Ortaöğretim okullarında örgütsel sağlık ile örgütsel vatandaşlık davranışları arasındaki ilişki. Türk Ĕ̆itim Bilimleri Dergisi, 6(4), 571-602.

Can N. (2010), Öğretmen liderliğinde müdürlerin etkisi. Dumlupınar Üniversitesi Sosyal Bilimler Dergisi, (27), 57- 66.

Çetin, Ş., Korkmaz, M. ve Çakmakçı, C. (2012). Dönüşümsel ve etkileşimsel liderlik ile lider-üye etkileşiminin öğretmenlerin örgütsel vatandaşlık davranışı üzerindeki etkisi. Kuram ve Uygulamada Eğitim Yönetimi Dergisi, 18(1), 7-36.

Covin, J.G. ve Slevin, D.P. (1991). A Conceptual model of entrepreneurship as firm behavior. Entrepreneurship Theory and Practice, 16(1), 725.

Dağlı, E. ve Çalık, T. (2016). İlköğretim okullarında müdürlerin kullandıkları etkileme taktiklerinin öğretmenlerin örgütsel vatandaşlık davranışları ve okul farkındalığı ile ilişkisi. Kuram ve Uygulamada Eğitim Yönetimi Dergisi, 22(1), 29-58.

DiPaola, M. F. ve Hoy, W. K. (2005). School characteristics that foster organizational citizenship behavior. Journal of School Leadership, 15(4), 387-406.

DiPaola, M. ve Tschannen-Moran, M. (2001). Organizational citizenship behavior in schools and its relationships to school climate. Journal of School Leadership, 11(5), 424-447.

Erdoğan, U. (2012). İlköğretim okullarının bürokratik yapıları ile öğretmenlerin örgütsel sosyalleşme düzeyleri arasındaki ilişki. Yayımlanmamış Yüksek Lisans Tezi, İnönü Üniversitesi Eğitim Bilimleri Enstitüsü, Malatya.

Field, A. (2009). Discovering statistics using SPSS. Dubai: Oriental Press. 
Fraenkel, J. R. ve Wallen, N. E (2006). How to design and evaluate research in education (6th Ed.). New York: McGraw-Hill.

Genç, N. (2007). Yönetim ve organizasyon. Ankara: Seçkin Yayıncılık.

Griffin, R. W. ve Moorhead, G. (2014). Organizational behavior: Managing people and organizations. Mason, $\mathrm{OH}$ : South Western Cengage Learning.

Güney, S. (2011). Örgütsel davranış (1. basım). Ankara: Nobel Akademi Yayıncilik.

Hirschhorn, L. (1997). Reworking authority: Leading and following in a postmodern organization. Cambridge, MA: MIT Press.

Hoy, W. K. ve Miskel, C. G. (2010). Eğitim yönetimi (Çev. Ed. S. Turan). Ankara: Nobel Akademi Yayıncilik.

Hoy, W. K. ve Sweetland, S. R. (2001). Designing better schools: The meaning and measure of enabling school structures. Educational Administration Quarterly, 37(3), 296-321.

İçerli, L. (2009). Örgüt yapısı ve örgütsel adalet arasındaki ilişkiler. Yayımlanmamış Doktora Tezi, Dokuz Eylül Üniversitesi Sosyal Bilimler Enstitüsü, İzmir.

Karasar, N. (2015). Bilimsel araştırma yöntemleri (28. basım). Ankara: Nobel Akademi Yayıncilık.

Kline, R. B. (2011). Principles and practice of structural equation modeling. New York, NY: Guilford.

Konovsky, M. A. ve Pugh, S. D. (1994). Citizenship behavior and social exchange. Academy of Management Journal, 37(3), 656-669.

Lambert, S. J. (2000). Added benefits: The link between work-life benefits and organizational citizenship behavior. Academy of Management Journal, 43(5), 801-815.

Matsuda, A. ve Matsuda, P. K. (2001). Autonomy and collaboration in teacher education: journal sharing among native and nonnative english-speaking teachers. The Catesol Journal, 13(1), 109-121

McGuigan, L. ve Hoy, W. K. (2006). Principal leadership: Creating a culture of academic optimism to improve achievement for all students. Leadership and Policy in Schools, 5(3), 203-229.

Messick, P. P. (2012). Examining relationships among enabling school structures, academic optimism and organizational citizenship behaviors. Unpublished Ph.D. Thesis, Auburn University, Auburn. 
Meydan, C. H. ve Şeşen, H. (2015). Yapısal eşitlik modellemesi AMOS uygulamaları. Ankara: Detay Yayıncilik.

Mintzberg, H. (2014). Örgütler ve yapıları (Çev. Ed. A. Aypay). Ankara: Nobel Akademi Yayıncılık.

Murphy, J. (2013). The architecture of school improvement. Journal of Educational Administration, 51(3), 252-263.

Oğuz, E. (2011). Öğretmenlerin örgütsel vatandaşlık davranışları ile yöneticilerin liderlik stilleri arasındaki ilişki. Kuram ve Uygulamada Ĕ̆itim Yönetimi Dergisi, 17(3), 377-403.

Oplatka, I. (2006). Going beyond role expectations: Toward an understanding of the determinants and components of teacher organizational citizenship behavior. Educational Administration Quarterly, 42(3), 385-423.

Organ, D. W. (1988). Organizational citizenship behavior: The good soldier syndrome. Lexington, MA: D.C. Heathand Company.

Owens, R. G. (2004). Organizational behavior in education: Adaptive leadership and school reform. Boston: Pearson.

Özer, N. ve Dönmez, B. (2013). Kolaylaştırıcı okul yapısı ölçeğinin Türkçe formunun psikometrik özelliklerinin yeniden değerlen-dirilmesi. Pegem Eğitim ve Öğretim Dergisi, 3(4), 57-68.

Özgür, B. (2011). Yönetim tarzları ve etkileri. Maliye Dergisi, 161, 215-230. Podsakoff, P. M., MacKenzie, S. B., Paine, J. B. ve Bachrach, D. G. (2000). Organizational citizenship behaviors: A critical review of the theoretical and empirical literature and suggestions for future research. Journal of Management, 26(3), 513-563.

Polat, S. ve Celep, C. (2008). Ortaöğretim öğretmenlerinin örgütsel adalet, örgütsel güven, örgütsel vatandaşlık davranışlarına ilişkin algıları. Kuram ve Uygulamada Eğitim Yönetimi Dergisi, 14(2), 307-331.

Robbins, S.P., ve Judge, T.A. (2013). Örgütsel davranış. (14. Baskıdan Çeviri). Erdem, İ. (Çev. Ed.), Ankara: Nobel Yayın Dağıtım.

Samancl, K. G. (2007). Örgütsel güven ve örgütsel vatandaşlık davranışı. Yayınlanmamış Yüksek lisans Tezi, Afyon Kocatepe Üniversitesi Sosyal Bilimler Enstitüsü, Afyonkarahisar.

Sezgin, F. (2005). Örgütsel vatandaşlık davranışları: Kavramsal bir çözümleme ve okul açısından bazı çıkarımlar. Gazi Üniversitesi Gazi Ĕ̆itim Fakültesi Dergisi, 25(1), 317-339. 
Sinden, J., Hoy, W. K. ve Sweetland, S. R. (2004). Enabling school structures: Principal leadership and organizational commitment of teachers. Journal of School Leadership, 14(2), 195-210.

Somech, A. ve Drach-Zahavy, A. (2000). Understanding extra-role behavior in schools: The relationships between job satisfaction, sense of efficacy, and teachers' extra-role behavior. Teaching and Teacher Education, 16(5-6), 649-659.

Somech, A. ve Ron, I. (2007). Promoting organizational citizenship behavior in schools: The impact of individual and organizational characteristics. Educational Administration Quarterly, 43(1), 38-66.

Sümer, N. (2000). Yapısal eşitlik modelleri: Temel kavramlar ve örnek uygulamalar. Türk Psikoloji Yazıları, 3(6), 49-74.

Tabachnick, B. G. ve Fidell, L. S. (2013). Using multivariate statistics (sixth ed.). Pearson, Boston.

Taşdan, M. ve Yılmaz, K. (2008). Adaptation to Turkish of organizational citizenship and organizational justice scales. TED Eğitim ve Bilim Dergisi, 33(150), 87-96.

Tekin, E. (2018). Lider-üye etkileşiminin örgütsel vatandaşlık davranışı üzerindeki etkisinde örgütsel adalet algısının aracılık rolü. BMIJ, 6(1), 291-314.

Titrek, O., Bayrakçı, M. ve Zafer, D. (2009). Öğretmenlerinin örgütsel vatandaşlık davranışlarına ilişkin görüşleri. Akademik Bakış Dergisi, 17, 1-28.

Tokgöz E. ve Seymen, O.A. (2013). Örgütsel güven, örgütsel özdeşleşme ve örgütsel vatandaşlık davranışı arasındaki ilişki: Bir devlet hastanesinde araştırma. Öneri Dergisi, 10(39), 61-76.

Weick, K. E. ve Sutcliffe, K. M. (2001). Managing the unexpected: Assuring high performance in an age of complexity. San Francisco: Jossey-Bass.

Wu, J. H., Hoy, W. K. ve Tarter, C. J. (2013). Enabling school structure, collective responsibility and a culture of academic optimism: Toward a robust model of school performance in Taiwan. Journal of Educational Administration, 51(2), 176-193.

Yaylacı, A. F. (2004). İlköğretim okulu öğretmen ve yöneticilerinin örgütsel vatandaşlık davranışları. (Yayımlanmamış doktora tezi), Ankara Üniversitesi Eğitim Bilimleri Enstitüsü, Ankara. 
Yılmaz, A. İ. ve Beycioğlu, K. (2017). Okullardaki bürokratik yapıya ilişkin öğretmen görüşleri. Anadolu Üniversitesi Eğitim Fakültesi Dergisi, 1(2), 1-23.

Yılmaz, K. (2009). Özel dershane öğretmenlerinin örgütsel güven düzeyleri ile örgütsel vatandaşlık davranışları arasındaki ilişki. Kuram ve Uygulamada Eğitim Yönetimi Dergisi, 15(59), 471-490.

Yılmaz, K. ve Taşdan, M. (2009). Organizational citizenship and organizational justice in Turkish primary schools. Journal of Educational Administration, 47(1), 108-126.

\section{Kaynakça Bilgisi / Citation Information}

Alev, S. (2019). Kolaylaştırıcı okul yapısı ve örgütsel vatandaşlık davranışları arasındaki ilişkinin incelenmesi. OPUS-Uluslararası Toplum Araştırmaları Dergisi, 10(17), 420-443. DOI: 10.26466/opus.518009 